\title{
Use of by-products for partial replacement of 3D printed concrete constituents; rheology, strength and shrinkage performance
}

\author{
Michail Papachristoforou, Vasilios Mitsopoulos, Maria Stefanidou \\ Laboratory of Building Materials, School of Civil Engineering, Aristotle University of Thessaloniki, Greece \\ papchr@civil.auth.gr,mitsopov@civil.auth.gr,stefan@civil.auth.gr
}

\begin{abstract}
In this paper, fly ash, ladle furnace slag and limestone filler were utilized in concrete used as material for additive manufacturing (3D printing). Fly ash and ladle furnace slag were used as a replacement of cement (30\% wt.) and limestone filler as a replacement of siliceous aggregates (50\% wt.). Workability of fresh concretes that contained these by-products was measured 0,15 and 30 minutes after mixing. Three different workability tests were conducted and compared: flow table, ICAR rheometer and an experimental method that measures the electric power consumption of the motor that rotates the screw extruder. Workability parameters that were measured were evaluated regarding printability of mixtures. Density, ultrasonic pulse velocity, compressive and flexural strength were measured on hardened concrete. Additionally, relative likelihood of cracking of different concrete mixtures was estimated by performing restrained shrinkage test (ASTM C1581). Results showed that use of fly ash or ladle furnace slag as binder, and limestone filler as aggregate decreases slightly the mechanical properties of concrete but improve its durability regarding cracking potential. Monitoring of electric power consumption of screw extruder motor was found to be an effective method for measuring easily real-time workability and define if a mixture is printable or not.
\end{abstract}

KEYwORDS. 3D printing, Concrete; Workability; ASTM C1581; Shrinkage.

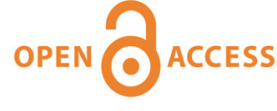

Citation: Papachristoforou, M., Mitsopoulos, V., Stefanidou, M., Use of by-products for partial replacement of $3 \mathrm{D}$ printed concrete constituents; rheology, strength and shrinkage performance, Frattura ed Integrità Strutturale, 50 (2019) 526-536.

Received: 12.01 .2019

Accepted: 22.05.2019

Published: 01.10.2019

Copyright: (C) 2019 This is an open access article under the terms of the CC-BY 4.0, which permits unrestricted use, distribution, and reproduction in any medium, provided the original author and source are credited.

\section{INTRODUCTION}

3 -D printing technology is an additive manufacturing technique in which a structure is built layer by layer with various printing materials, based on a three dimensional (3D) model data. The first to introduce this technology in the construction industry using concrete as printing material was Khoshnevis who invented the technique of contour crafting [1]. There has been a growing interest over the past decade upon 3D printing for civil engineering applications due to the advantages this method has compared to traditional concrete placing, such as the ability to construct freeform geometry without the need of formwork, construction speed and minimization of waste material and labour cost. Today there are many research groups and industries working on the topic with successful applications (Loughborough University [2], D-Shape [3], 
ApisCor [4], WASP [5], CyBe Constructions [6], WINSUN [7]), however daily practice still seems far away. This comes from the fact that construction industry is risk adverse and conservative in its practice but also because there are technical some challenges that need to be overcome to unlock and trigger all opportunities from 3D printing in building sector [8].

Perhaps the greatest challenge of 3D printed concrete is to have a successful printing, meaning that the printed structure has the desired shape and material properties. Printing system (type of printer, pump, printhead) and concrete fresh properties are the two factors that affect significantly printing quality. There are not any commercially available printers for concrete so researchers and industries have developed different types of prototype printers and printheads and properly configure mix design. Focusing on the material, it must be flowable enough so that it can be extruded through the nozzle, meaning that the pump exerts enough stress to exceed the yield stress of concrete, causing it to flow and extrude through the nozzle. But once the layer is extruded, the concrete yield stress should be higher than the stress due to self weight in order to resist deformation. Furthermore, the yield stress of the extruded concrete should increase even more in order to support the upcoming layers through thixotropy and cement hydration. Therefore, concrete yield stress that can be measured using Self Compacting Concrete (SCC) tests becomes the most important parameter for mixture design and has an optimum range in which the material is both extrudable and buildable [9]. There are various research works studying fresh properties of 3D printed concrete using different tests. Kazemian et al. [10] proposed a framework for accepting on not a mixture as printable. Workability of a fresh printing mixture was tested using the flow table test and studied in terms of print quality and shape stability using measures of surface quality and dimensions of printed layers. Perrot et al. [11] used a rotational rheometer to measure yield stress and compare the critical stress related to the plastic deformation with the vertical stress acting on the first printed layer. However, regardless the test adopted, testing procedure requires a sample of the material in order to be performed, meaning that printing procedure must be stopped for testing. For a given printing system, real time monitoring and active control of rheology during production by adding automatically chemical additives seems to be the most robust approach in order to address this challenge [8].

Mixture proportions of concrete for 3D printing differ from ordinary one. Regarding aggregates, in most cases only fine natural or crushed aggregate is used in order to allow the material to pass through the small pipes and nozzles at the printing head. While in ordinary concrete cement quantity is $270-350 \mathrm{~kg} / \mathrm{m}^{3}$, concrete mixtures for 3D printing use higher amounts of cement $\left(600-900 \mathrm{~kg} / \mathrm{m}^{3}\right)$ in order to improve consistency and strength [12]. However, increased cement content in combination with the absence of formwork that protects the freshly placed concrete against desiccation make the concrete volume more prone to shrinkage cracking compared to conventionally placed concrete. The use of supplementary cementitious materials (SCM) such as fly ash, silica fume or slag as partially replacement of cement can improve crack resistance of concrete at early age [13]. Chemical additives are also used to control workability and open time of fresh concrete for 3D printing which are related to printability and buildability [14]. Printability can be defined as the capacity of concrete to pass through the small pipes and nozzles at the printing head and extrude continuously without blockage or fracture occurs, and buildability as the capacity to maintain its shape once deposited and not collapse under the load of subsequent layers [10]. The use of by-products in the production of 3D printed concrete has not been studied in the literature. The scope for using such alternative materials in concrete production is twofold; it can provide some technical improvements to the final product, but it is also expected to be beneficial from an environmental point of view [15]. This paper aims at developing effective and eco-friendly concrete mixtures for 3D printing by using by-products as binders and aggregates, measure fresh properties of these mixtures, correlate them with printability and buildability and finally, test mechanical properties and durability of hardened concretes in order to obtain the optimum materials and proportions.

\section{EXPERIMENTAL PROGRAM}

\section{Materials and printing system}

he industrial by-products that were used were high calcium $\left(\mathrm{CaO}_{\text {free }}\right.$ content $10 \%$ wt.) Fly Ash (FA), Ladle Furnace Slag (LFS) and Limestone Filler (LF). FA is produced in lignite fire power plants, LFS during steel production process and LF comes as a by-product from crushing of limestone. FA and LFS can be used as SCMs and increase durability of concrete $[16,17,18]$, while LF is successfully used in self compacted concrete as filler material [19,20].

Two sets of mixtures were produced in the laboratory, one with $500 \mathrm{~kg} / \mathrm{m}^{3}$ and one with $830 \mathrm{~kg} / \mathrm{m}^{3}$ total binder quantity. $10 \%$ of the binder was silica fume and $90 \%$ was cement type II $52.5 \mathrm{~N}$. In some mixtures, $30 \%$ wt. of cement was replaced by FA or LFS passing from the $100 \mu \mathrm{m}$ sieve, while in others, LF replaced $50 \%$ wt. of siliceous river sand aggregates. The granulometry of LF, river sand and combination of both is given in Fig.1. The proportions of all the mixtures produced are presented in Tables 1 and 2, along with the type of by-products used in each mixture. From preliminary tests conducted, optimum superplasticizer and water quantities were obtained in order to have adequate and similar workability for all 
mixtures. Superplasticizer addition rate ranged from 2-3.4 \% of binder and water to cement ratio 0.47-0.57 and 0.34-0.37 for the mixtures with 500 and $830 \mathrm{~kg} / \mathrm{m}^{3}$ binder respectively.

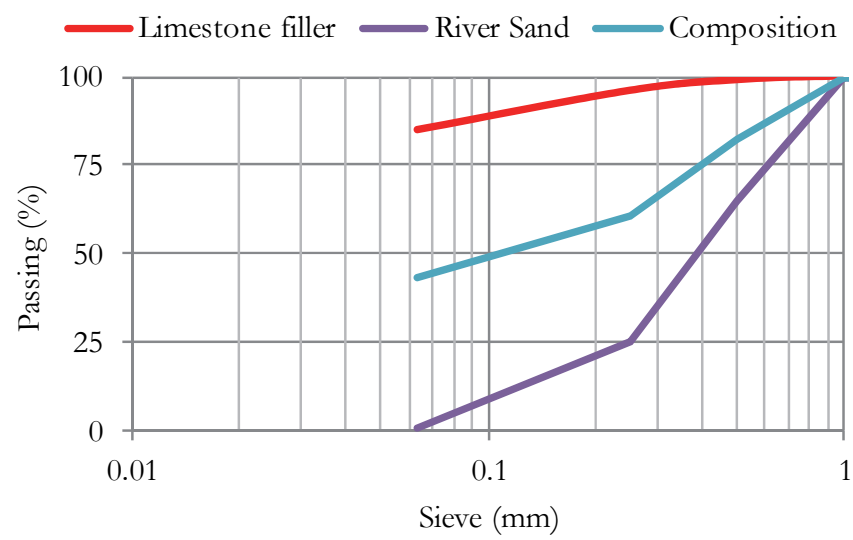

Figure 1: Granulometry of aggregates used.

\begin{tabular}{|c|c|c|c|c|c|c|}
\hline \multicolumn{2}{|c|}{ Materials $\left(\mathrm{kg} / \mathrm{m}^{3}\right)$} & CL1 & FL1 & F1 & LL1 & L1 \\
\hline \multicolumn{2}{|c|}{ Cement II52,5N } & 450 & 350 & 350 & 350 & 350 \\
\hline \multicolumn{2}{|c|}{ Silica fume } & 50 & 50 & 50 & 50 & 50 \\
\hline \multicolumn{2}{|l|}{ Fly Ash } & - & 100 & 100 & - & - \\
\hline \multicolumn{2}{|c|}{ Ladle Furnace slag } & - & - & - & 100 & 100 \\
\hline \multicolumn{2}{|c|}{ Limestone filler } & 667 & 667 & - & 667 & - \\
\hline \multicolumn{2}{|c|}{ Siliceous sand } & 667 & 667 & 1333 & 667 & 1333 \\
\hline \multicolumn{2}{|l|}{ Water } & 289 & 280 & 242 & 280 & 237 \\
\hline \multicolumn{2}{|c|}{ Superplasticizer } & 17 & 16 & 14 & 16 & 14 \\
\hline \multirow{2}{*}{$\begin{array}{c}\text { By- } \\
\text { products } \\
\text { used }\end{array}$} & Binder & - & Fly Ash & Fly Ash & LFS & LFS \\
\hline & Aggregate & $\begin{array}{c}\text { Limestone } \\
\text { filler }\end{array}$ & $\begin{array}{c}\text { Limestone } \\
\text { filler }\end{array}$ & - & $\begin{array}{c}\text { Limestone } \\
\text { filler }\end{array}$ & - \\
\hline
\end{tabular}

Table 1: Mixture proportions for $500 \mathrm{~kg} / \mathrm{m}^{3}$ binder.

\begin{tabular}{|c|c|c|c|c|c|c|}
\hline \multicolumn{2}{|c|}{ Materials $\left(\mathrm{kg} / \mathrm{m}^{3}\right)$} & CL2 & FL2 & $\mathrm{F} 2$ & LL2 & $\mathrm{L} 2$ \\
\hline \multicolumn{2}{|c|}{ Cement II52,5N } & 747 & 582 & 582 & 582 & 582 \\
\hline \multicolumn{2}{|c|}{ Silica fume } & 83 & 83 & 83 & 83 & 83 \\
\hline \multicolumn{2}{|l|}{ Fly Ash } & - & 165 & 165 & - & - \\
\hline \multicolumn{2}{|c|}{ Ladle Furnace slag } & - & - & - & 165 & 165 \\
\hline \multicolumn{2}{|c|}{ Limestone filler } & 550 & 550 & - & 550 & - \\
\hline \multicolumn{2}{|c|}{ Siliceous sand } & 550 & 550 & 1100 & 550 & 1100 \\
\hline \multicolumn{2}{|l|}{ Water } & 308 & 308 & 281 & 308 & 281 \\
\hline \multicolumn{2}{|c|}{ Superplasticizer } & 17 & 20 & 17 & 19 & 16 \\
\hline \multirow{2}{*}{$\begin{array}{c}\text { By- } \\
\text { products } \\
\text { used }\end{array}$} & Binder & - & Fly Ash & Fly Ash & LFS & LFS \\
\hline & Aggregate & $\begin{array}{l}\text { Limestone } \\
\text { filler }\end{array}$ & $\begin{array}{l}\text { Limestone } \\
\text { filler }\end{array}$ & - & $\begin{array}{l}\text { Limestone } \\
\text { filler }\end{array}$ & - \\
\hline
\end{tabular}

Table 2: Mixture proportions for $830 \mathrm{~kg} / \mathrm{m}^{3}$ binder. 
A prototype printhead was introduced to extrude the mixtures. The diameter of the nozzle was $2 \mathrm{~cm}$ and a screw-kind extrusion system was selected for the extrusion process due to some of the advantages and easiness it offers in comparison to other extrusion methods (syringe extrusion) [21].

\section{Concrete tests}

Fresh concrete properties were estimated using a rotational rheometer [22,23] and the flow table test according to EN 1015-3 [24]. These tests were conducted 0, 15 and 30 min after mixing in order to determine the rate of which the workability is lost for the given 3D printing system and materials. However, performing of these tests requires extracting an adequate quantity of the material from the printing system and results are obtained after the test is completed. For this reason, a new method was implemented in order to estimate real-time workability of fresh concrete during printing by recording real time energy consumption of screw extruder motor. The method was calibrated with the rotational rheometer ASTM C1749 test [23] for measuring rheology characteristics of SCC mixtures and the flow table test. The rotational rheometer test uses a rotating four-bladed vane. A strain gage measures deformation of the shaft rotating the vane and transforms it to torque and finally, yield stress. With the proposed method, the vane is substituted by the screw extruder and the complex strain gage recording apparatus fitted on the rotating shaft by a much simpler wattometer that records the Watts of the motor that rotates the extruder. The same principle is used in ready-mix concrete plants where the power consumption of the mixer motor is recorded during mixing, making possible for the operator to adjust water quantity in order to obtain desired workability. By measuring real-time workability of mixture, it is possible to alter it manually or automatically by adding chemical additives in the print-head (superplasticizer, viscosity modifier, retarder etc.), using appropriate equipment as proposed by Gosselin et al. [25]. The final workability parameters that were measured are presented in Table 3.

\begin{tabular}{lll}
\hline Standard & Test apparatus & Parameter tested \\
ASTM C 1749 & Rotational Rheometer & Static Yield Stress (Pa) \\
EN 1015-3:1999 & Flow table & Expansion (mm) \\
& $\begin{array}{l}\text { Real time monitoring of } \\
\text { workability }\end{array}$ & $\begin{array}{l}\text { Electric power consumption of electric } \\
\text { motor rotating screw extruder }(\mathrm{W})\end{array}$ \\
\hline
\end{tabular}

Table 3: Testes for measuring workability of 3D printing concrete.

The threshold values of the above parameters were obtained in order to characterize the concrete mixture as printable, meaning that it can be extruded from the nozzle, and buildable. Buildability was estimated by the number of layers of the printing specimen that can be achieved without collapse. Malaeb et al. [26] proposed that 5 layers were considered to be the target and this was the method that was adopted. Additionally, shape stability was another criterion for buildability and was estimated by measuring the dimensions of the first and fifth layer. The height ratio of the first layer versus fifth layer should be kept around 1 in order to accept the mixture as printable. Final criteria for printability and buildability are given in Table 4.

\begin{tabular}{|c|c|c|}
\hline $\begin{array}{l}\text { Characteristics of 3D } \\
\text { printing concrete }\end{array}$ & Accepted & Not accepted \\
\hline Printability & $\begin{array}{l}\text { 1. The mixture is extruded through } \\
\text { the nozzle } \\
\text { 2. Good printing quality meaning no } \\
\text { voids, no dimensional variations of } \\
\text { extruded material }\end{array}$ & $\begin{array}{c}\text { If } 1 \text { or } 2 \\
\text { do not apply }\end{array}$ \\
\hline Buildability & $\begin{array}{l}\text { 3. Five layers of printing material can } \\
\text { be achieved without collapse } \\
\text { 4. Height of } 1^{\text {st }} \text { layer versus height of } \\
5^{\text {th }} \text { layer } \sim 1\end{array}$ & $\begin{array}{c}\text { If } 3 \text { or } 4 \\
\text { do not apply }\end{array}$ \\
\hline
\end{tabular}

Table 4: Criteria for accepting concrete mixture as printable or not.

Regarding hardened concrete, compressive strength was measured on 40x40x40 mm cubes and 3-point flexural strength on 40x40x160 mm prisms after 28 days of curing in the humidity chamber. Additionally, density and Ultrasonic Pulse Velocity (UPV) of concretes were also recorded. Volume stability of mixtures, which is very important since shrinkage 
problems can be severe in 3D printing concrete due to high cement paste quantity, was also tested according to ASTM C1581-04 [27]. The procedure can be used to determine the effects of variations in the proportions and material properties of mortar or concrete on cracking due to both drying shrinkage and deformations caused by autogenous shrinkage and heat of hydration. The advantage of this test is that is more realistic since it measures concrete shrinkage under restrained conditions which occur in real applications. The apparatus consists of a steel ring with an outside diameter of $330 \mathrm{~mm}$ and height $152 \mathrm{~mm}$ and two strain gages at midheight locations on the interior surface of the steel ring along a diameter. The base, the outside steel ring surface and another outer ring with inner diameter $406 \mathrm{~mm}$ are used as a mould and concrete is poured. As concrete shrinks, it applies stress on the inner steel ring which is recorded in the form of deformation measured from the strain gages attached, until cracking occurs. Results of the test are the age of concrete at cracking (days) and the stress rate at cracking ((MPa/day). In Fig.2, a crack formed on concrete can be seen while Fig. 3 shows a typical diagram of age versus ring strain obtained from the measurements.

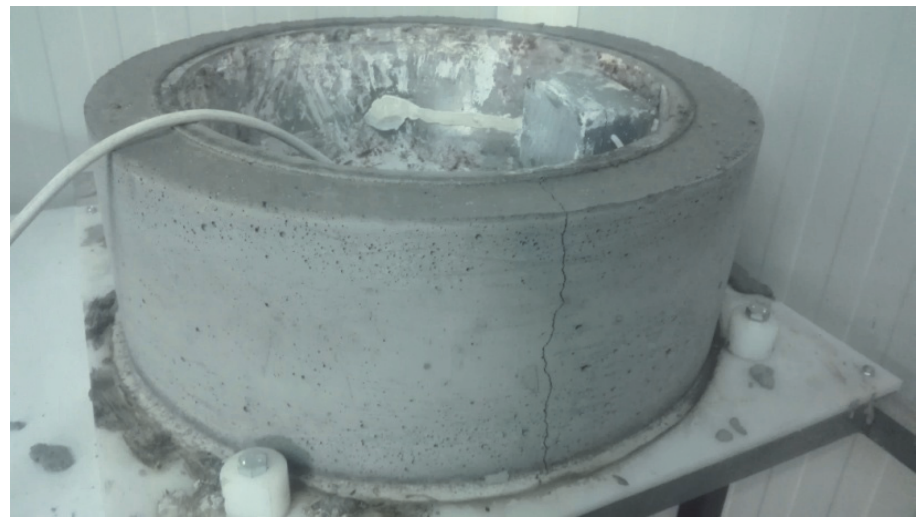

Figure 2: Formation of crack on concrete due to restrained shrinkage.

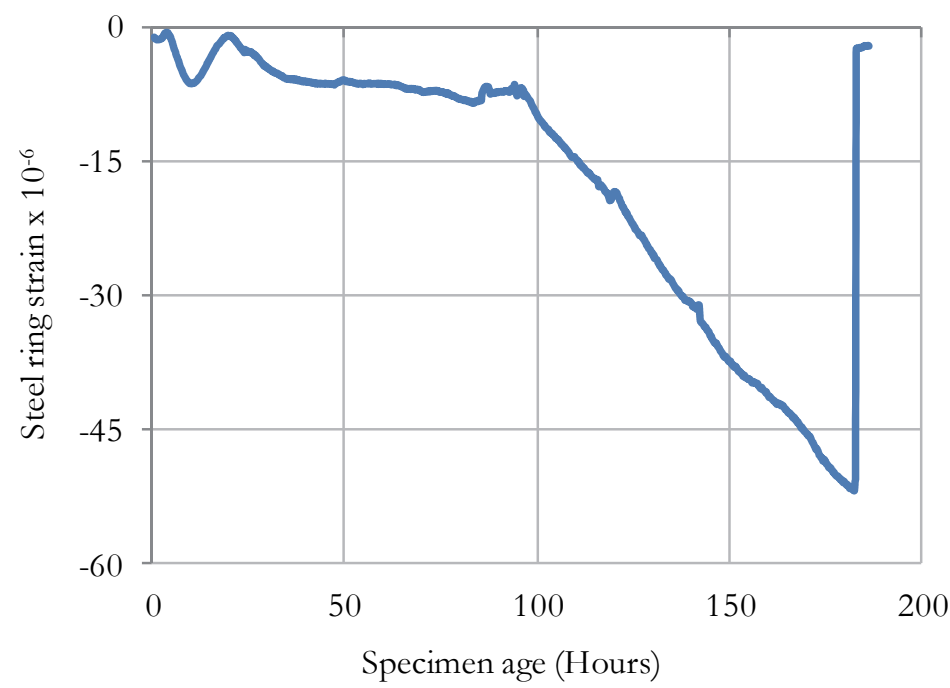

Figure 3: Age versus steel ring stress obtained from the restrained shrinkage test.

\section{Results}

Results of workability 0,15 and 30 minutes after mixing are given in Tables 5 and 6 . For the given printing system, it was soon realized that flow table expansion values, in order the mixture to be printable, should be between 18 and $24 \mathrm{~cm}$. From the other tests, accurate threshold values could not be obtained. In Figs.(4,5), flow table expansion versus the other parameters is given along with least squares regression lines and printable window (blue area with expansion 18-24 cm). For expansion less than $15 \mathrm{~cm}$ measured in some mixtures, no further testing was conducted since the mixtures were very stiff and could not be extruded. For the series of mixtures with low binder content (Table 5), three out of five were considered as printable only for 0 minutes after mixing. After 15 minutes, all of the mixtures were considered as not printable. On the other hand, mixtures with high binder content (Table 6) could be extruded but collapse 0 minutes after 
mixing, however printable mixtures were observed after 15 and even after 30 minutes. Comparison of binder quantity with the workability parameters tested shows that when binder content increases, values of expansion and yield stress are increased. Power consumption however is decreased and this can be attributed to the fact that higher quantity of cement renders to lower quantity of aggregate in a given volume of concrete and consequently, less friction induced by the aggregates in the moving parts of the screw extruder. Mixtures with FA seem to lose more rapidly workability compared to mixtures with cement or cement and LFS as binder. No clear results were observed regarding the type of aggregates.

\begin{tabular}{|c|c|c|c|c|c|c|}
\hline & & CL1 & FL1 & $\mathrm{F} 1$ & LL1 & L1 \\
\hline \multirow{3}{*}{ Expansion } & $0^{\prime}$ & 21 & 22 & 16.5 & 15.5 & 20.5 \\
\hline & $15^{\prime}$ & 16.5 & 17,5 & - & - & 17 \\
\hline & $30^{\prime}$ & - & 15,5 & - & - & - \\
\hline \multirow{3}{*}{$\begin{array}{l}\text { Yield stress } \\
\qquad(\mathrm{Pa})\end{array}$} & $0^{\prime}$ & 120 & 90 & 970 & 730 & 120 \\
\hline & $15^{\prime}$ & 1170 & 410 & - & - & 1170 \\
\hline & $30^{\prime}$ & - & 610 & - & - & - \\
\hline \multirow{3}{*}{$\begin{array}{l}\text { Power } \\
\text { consumption } \\
\text { of screw } \\
\text { extruder } \\
\text { motor (W) }\end{array}$} & $0^{\prime}$ & 732 & 680 & 741 & 812 & 694 \\
\hline & $15^{\prime}$ & 773 & 740 & - & - & 790 \\
\hline & $30^{\prime}$ & - & 784 & - & - & - \\
\hline
\end{tabular}

Table 5: Workability results for mixtures with $500 \mathrm{~kg} / \mathrm{m}^{3}$ binder.

\begin{tabular}{|c|c|c|c|c|c|c|}
\hline & & CL2 & FL2 & $\mathrm{F} 2$ & LL2 & L2 \\
\hline \multirow{3}{*}{ Expansion } & $0^{\prime}$ & 30 & 28 & 29 & 22 & 23,5 \\
\hline & $15^{\prime}$ & 26 & 25 & 24 & 16,5 & 21 \\
\hline & $30^{\prime}$ & 23.5 & 18 & 19 & 15 & 18.5 \\
\hline \multirow{3}{*}{$\begin{array}{l}\text { Yield stress } \\
\qquad(\mathrm{Pa})\end{array}$} & $0^{\prime}$ & 90 & 0 & 0 & 30 & 90 \\
\hline & $15^{\prime}$ & 260 & 730 & 690 & 700 & 260 \\
\hline & $30^{\prime}$ & 440 & 1020 & 980 & 730 & 440 \\
\hline \multirow{3}{*}{$\begin{array}{c}\text { Power } \\
\text { consumption } \\
\text { of screw } \\
\text { extruder } \\
\text { motor }(\mathrm{W})\end{array}$} & $0^{\prime}$ & 615 & 605 & 605 & 651 & 643 \\
\hline & $15^{\prime}$ & 631 & 633 & 647 & 679 & 669 \\
\hline & $30^{\prime}$ & 647 & 684 & 665 & 698 & 683 \\
\hline
\end{tabular}

Table 6: Workability results for mixtures with $830 \mathrm{~kg} / \mathrm{m}^{3}$ binder.

In Fig.6, mixture F2 with river sand as aggregate and part of binder FA, can be seen 0 (left) and 15 minutes (right) after mixing. The mixture on the left, even though it fulfills criteria 1,2 and 3, does not meet criteria 4 regarding buildability, since height ratio of 1 st layer versus 5 th is 0.3 , so it is characterized as not printable. On the other hand, the right specimen fulfills all 4 criteria and is characterized as printable.

Regarding hardened concrete properties, density of concretes with 500 and $830 \mathrm{~kg} / \mathrm{m}^{3} \mathrm{binder}$ was 2100 and $2225 \mathrm{~kg} / \mathrm{m}^{3}$, respectively. Compressive and flexural strength of mixtures is given in Figs.(7,8). Mixture with no SCMs as binder reached a compressive strength of $70 \mathrm{MPa}$. Substituting 30\% of cement with SCMs reduces compressive strength to $55 \mathrm{MPa}$ and flexural strength from 12.1 to 8.7 MPa. Similar strength development was observed for both FA and LFS mixtures. Slightly lower strength was measured only in mixtures with FA, when limestone filler substituted 50\% of natural sand. As expected, higher binder content showed increased strength. UPV, a non destructive method to estimate strength, was also measured on specimens with the same moisture conditions and correlated with experimental results of compressive strength (Fig.9). 


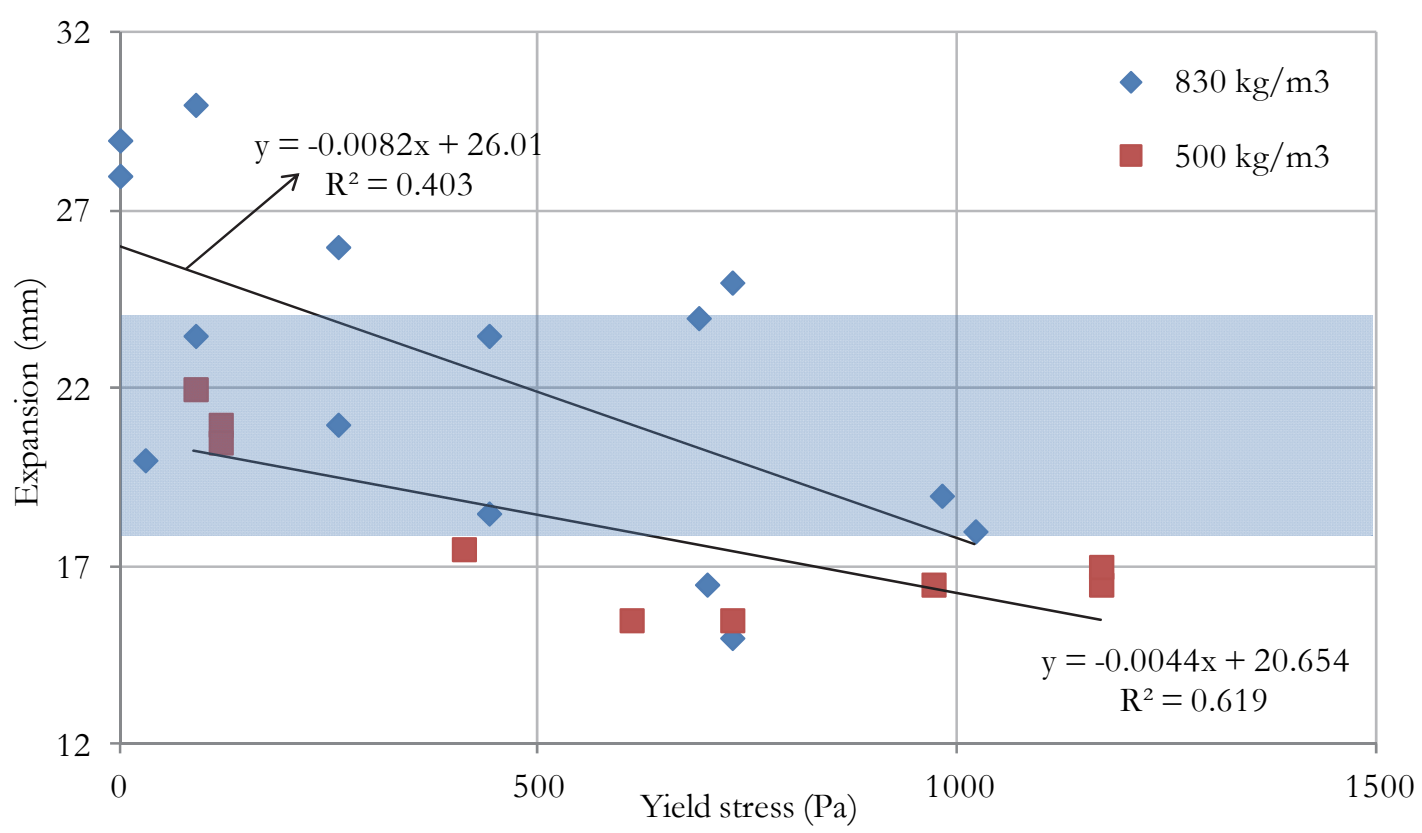

Figure 4: Yield stress versus expansion along with printable window (blue area).

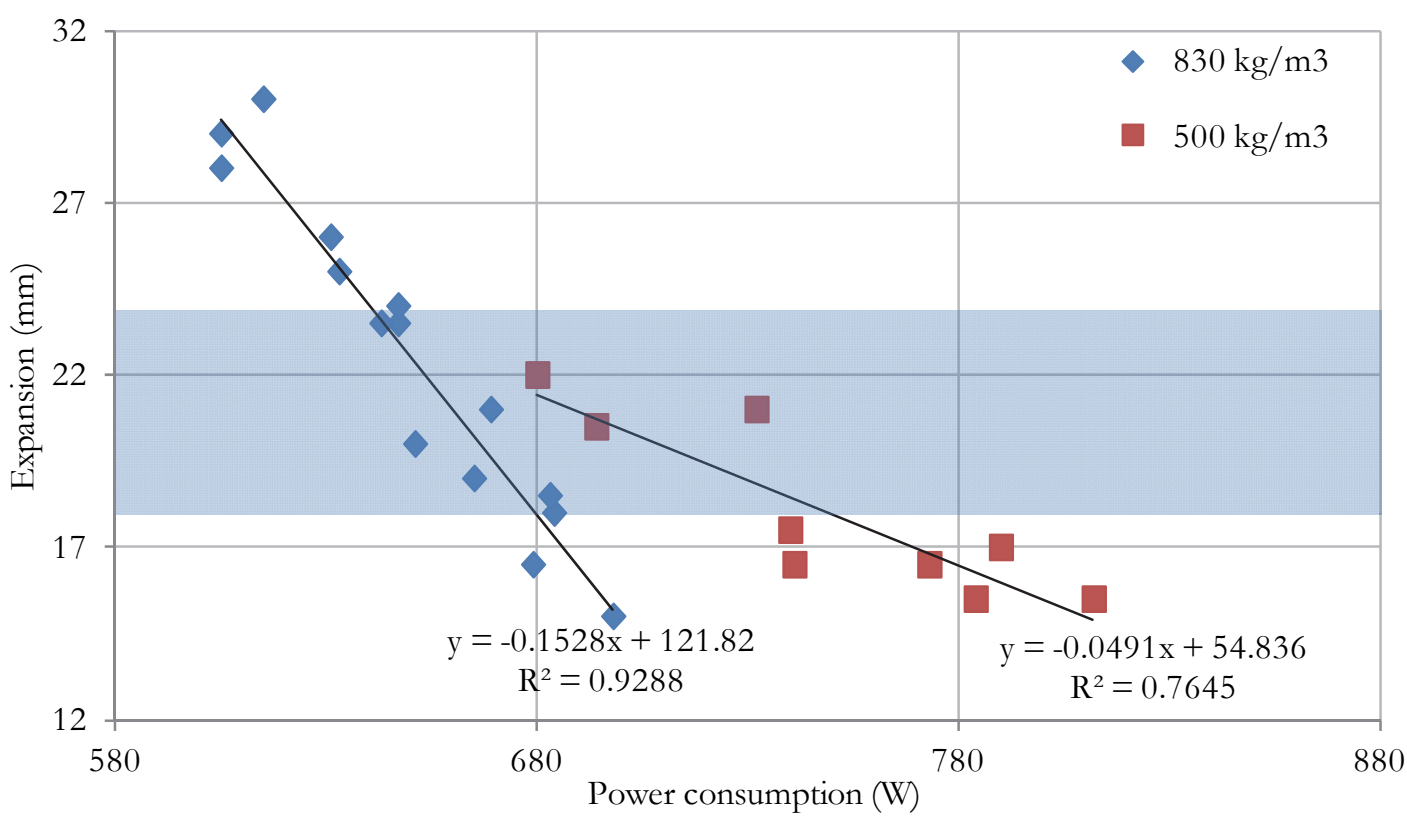

Figure 5: Power consumption of screw extruder motor versus expansion along with printable window (blue area).

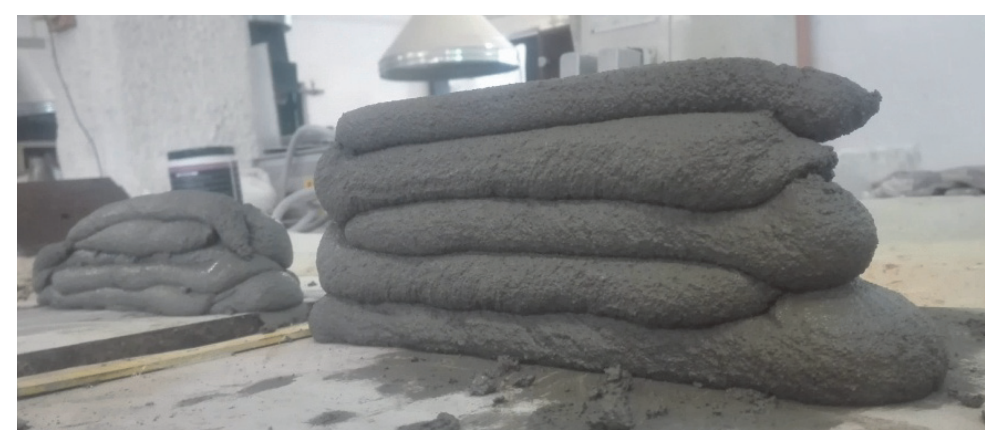

Figure 6: Difference on printing quality due to different workability of the same mixture 0 (left) and 15 minutes (right)after mixing. 
Results of the measurements of restrained shrinkage according to ASTM C1581 are given in Figs.(10,11). Mixtures with FA showed the best results since they lasted longer before crack formation occurs. For $830 \mathrm{~kg} / \mathrm{m}^{3}$ binder, the mixture with FA cracked after 7.64 days while the mixture with no SCMs only after 4.88 days. Mixtures with LFS had again better performance compared to one with no SCMs as binder, but not as good as FA based mixtures. Use of LF as aggregate improves the time at cracking compared to mixtures with no LF. Similar results were obtained from the stress rate calculation. Mixtures with no SCMs induced higher stress to the ring compared to the other mixtures.

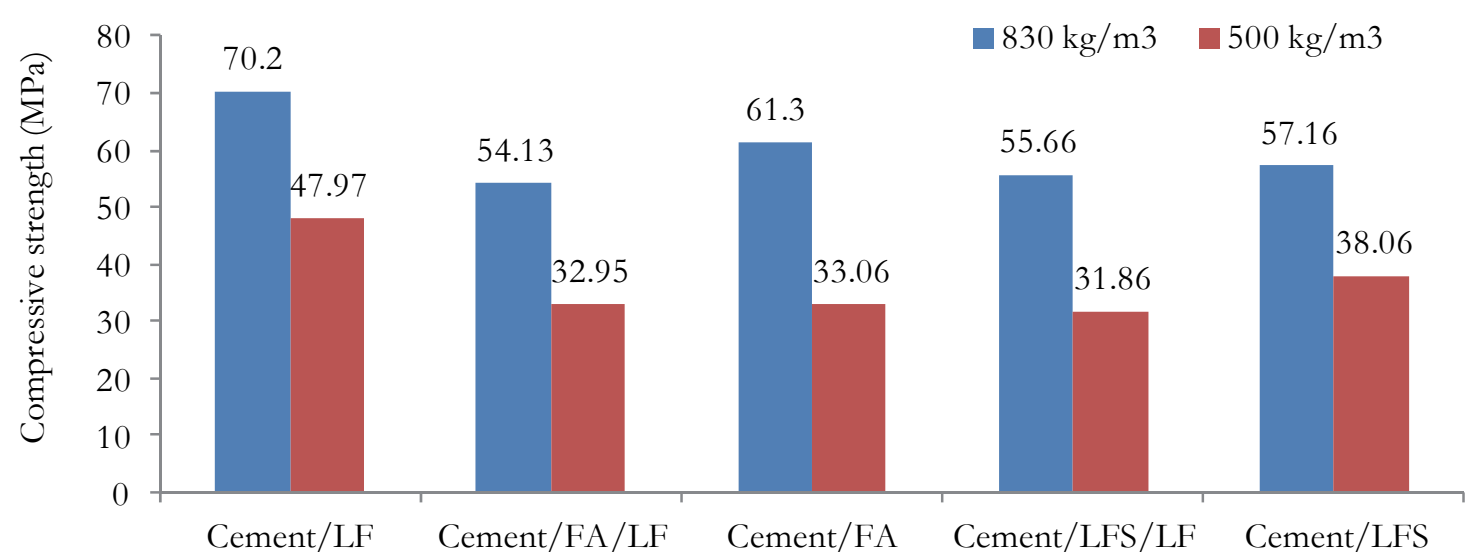

Figure 7: Compressive strength of mixtures with different binder content and materials used.

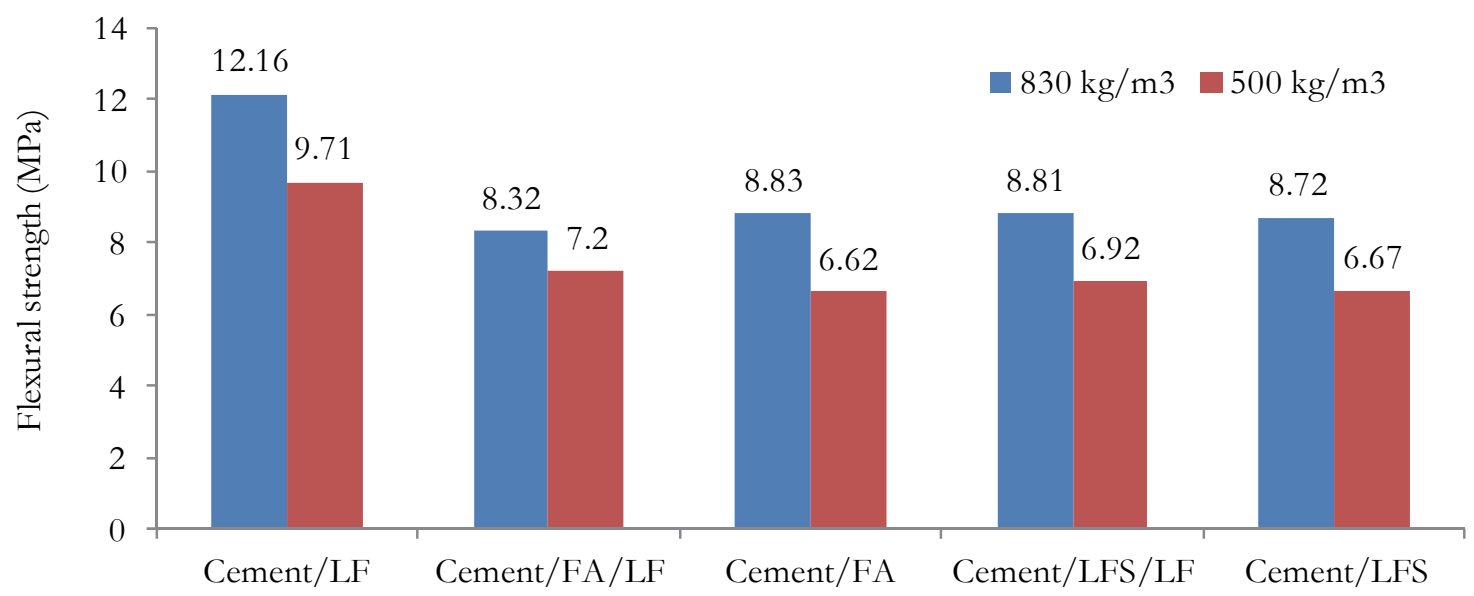

Figure 8: Flexural strength of mixtures with different binder content and materials used.

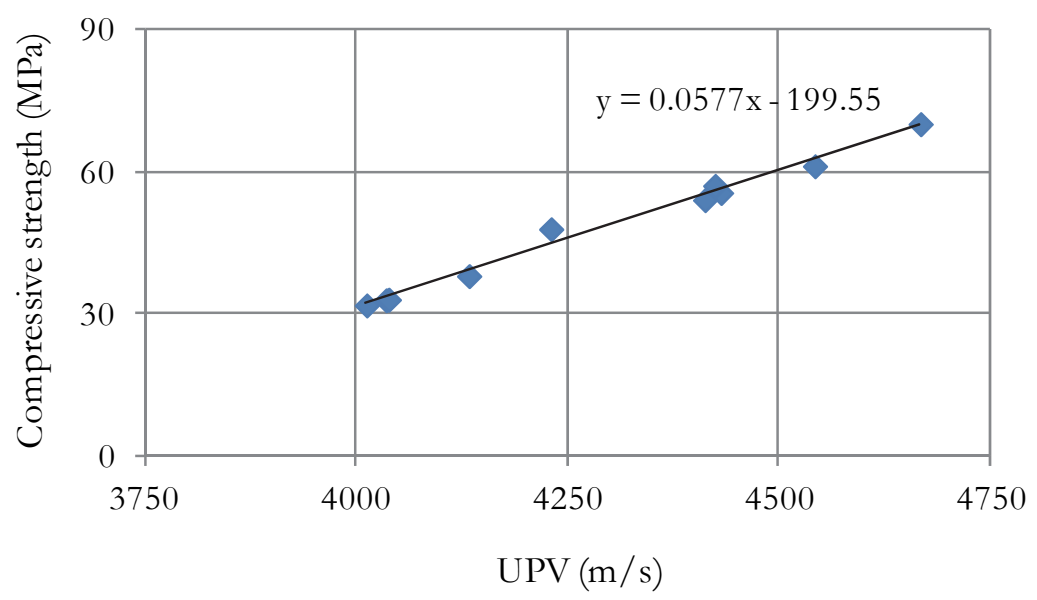

Figure 9: Ultrasonic Pulse Velocity versus compressive strength of mixtures. 


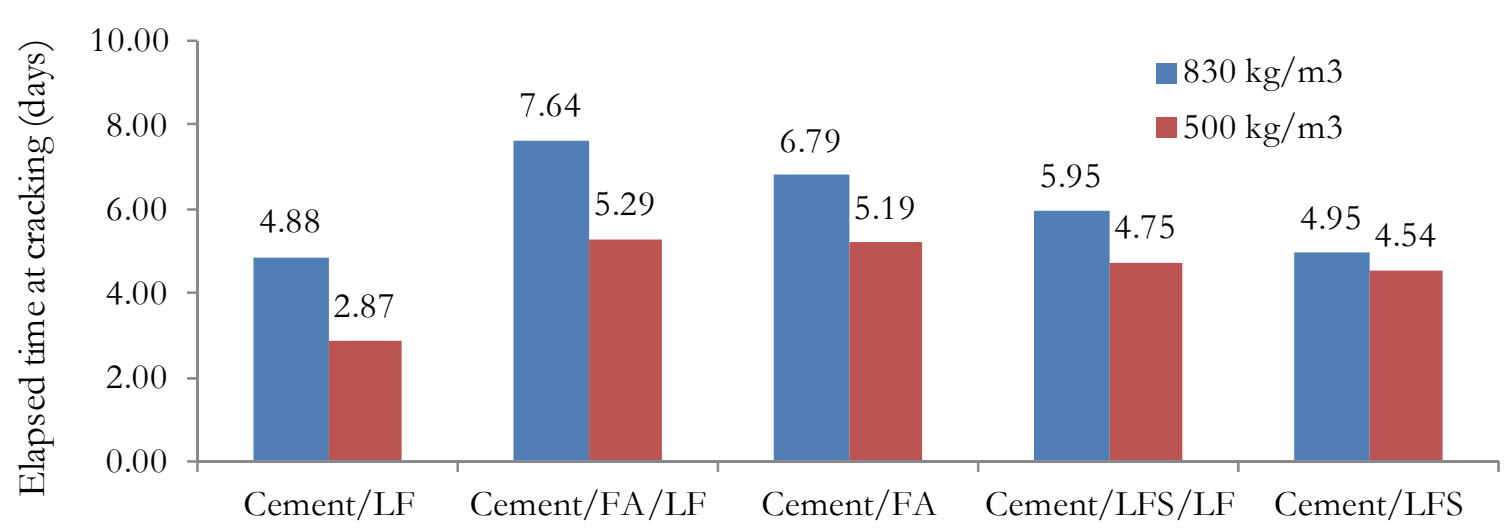

Figure 10: Time from molding to cracking for different mixtures.

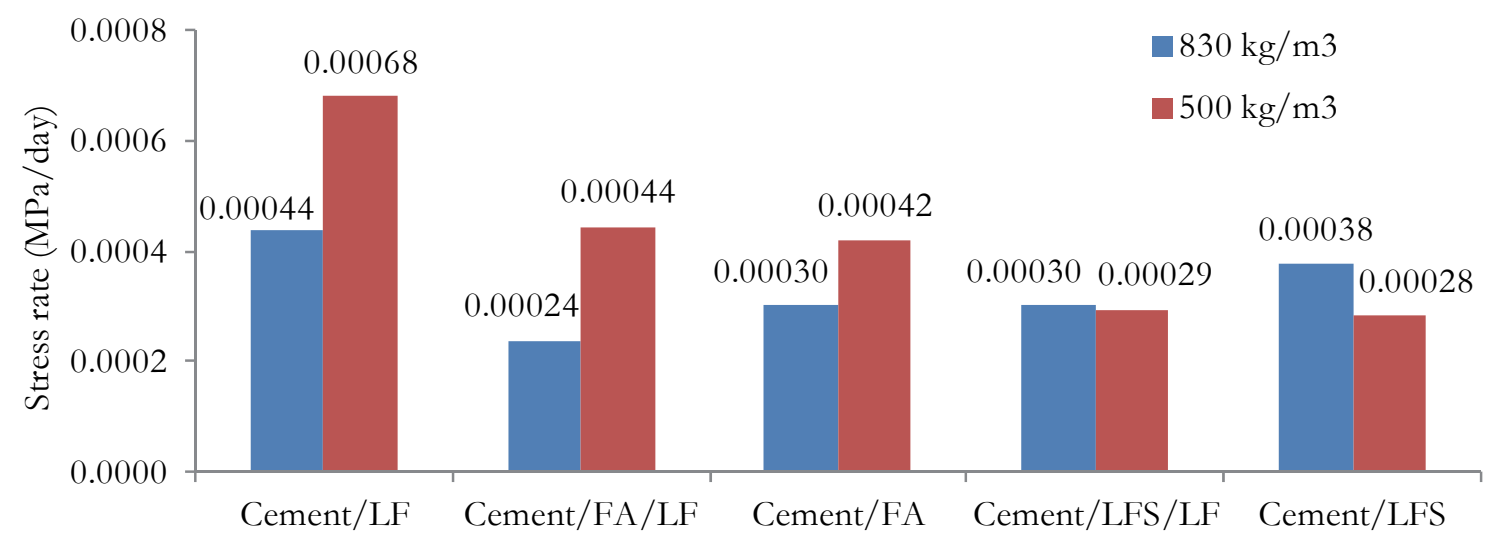

Figure 11: Stress rate at cracking for different mixtures.

\section{CONCLUSIONS}

hree by-products, Fly ash, Ladle Furnace Slag and Limestone Filler, were used successfully in the production of concrete that can be applied with the 3D printing technique. Workability and rheology of fresh concrete was measured by three different tests. The flow table expansion test described in the EN 1015-3 was the most consistent one, and values of expansion between 18 and $24 \mathrm{~cm}$ were the optimum in order the mixture to be printed with the printing system used. Electric power consumption of the motor that rotates the screw extruder was the method used for measuring real-time workability of the mixtures, making it possible to modify it on time in real scale applications by adding chemical additives during printing. Regarding the type of materials used, mixtures with FA seem to lose more rapidly workability compared to mixtures with cement or cement and LFS as binder. However, this reduction of workability could possibly be addressed by using retarder admixtures.

Regarding hardened concrete, ultrasonic pulse velocity showed very good correlation with compressive strength measured experimentally, proving that it can be a reliable non-destructive testing of estimating strength of concrete on 3D printed concrete structures. However, for 3D concrete performance testing, the engineers must take into account the interface zone between layers.

Concerning the alternative binders used, when FA or LFS substituted 30\% of cement, compressive strength dropped 20\% and flexural strength $32 \%$. Natural sand substitution by LF had minimum effect on strength development. On the contrary, shrinkage of concrete under restrained conditions was lower for mixtures produced with FA, LFS and LF. FA showed the best results (57\% improvement compared to mixture with no SCMs) followed by mixtures with LFS (22\% improvement compared to mixture with no SCMs). Utilization of LF again improved shrinkage behaviour, since time required for cracking increase by 12.5 to $20.5 \%$. Overall, lower cracking potential of the mixtures with the by-products can compensate lower strength performance, especially in case of 3D printing plain concrete, where there is no steel reinforcement to bear tensile loads induced under restrained concrete shrinkage and further research is suggested. 


\section{REFERENCES}

[1] Khoshnevis, B. (2004). Automated construction by contour crafting-related robotics and information technologies. Automation in Construction, 13(1), pp. 5-19. DOI: 10.1016/j.autcon.2003.08.012.

[2] Lim, S., et al. (2011). Development of a viable concrete printing process. Proc. 28 $8^{\text {th }}$ International Symposium on Automation and Robotics in Construction, (ISARC2011), Seoul, South Korea, pp. 665-670.

[3] Cesaretti, G., Dini, E., De Kestelier, X., Colla, V. and Pambaguian, L. (2014). Building components for an outpost on the Lunar soil by means of a novel 3D printing technology. Acta Astronautica, 93, pp. 430-450.

DOI:10.1016/j. actaastro.2013.07.034.

[4] website-6. (2019). ApisCor | en. [online] Available at: https://www.apis-cor.com/en [Accessed 19 Jan. 2019].

[5] 3dwasp.com. (2019). Stampanti 3d | WASP | Azienda leader nelsettoredellastampa 3D. [online] Available at: https:// www.3dwasp.com.

[6] CyBe Construction. (2019). CyBe Construction: Redefining construction by enabeling 3d concrete printing by providing hardware, software, material, education, certification and business development. [online] Available at: https://cybe.eu

[7] Winsun3d.com. (2019). Contact us- Yingchuang Building Technique (Shanghai) Co.Ltd. (WinSun). [online] Available at: http://www.winsun3d.com/En/Contact/ [Accessed 19 Jan. 2019].

[8] Schutter, G.D., Lesage, K., Mechtcherine, V., Nerella, N.V., Habert, G., Agusti-Juan, I. (2018). Vision of 3D printing with concrete - Technical, economic and environmental potentials. Cement and Concrete Research, 112, pp. 25-36. DOI: $10.1016 /$ j.cemconres.2018.06.001.

[9] Rahul, A.V., Santhanam, M., Meena, H., Ghani, Z. (2019). 3D printable concrete: Mixture design and test methods. Cement and Concrete Composites, 97, pp. 13-23. DOI: 10.1016/j.cemconcomp.2018.12.014.

[10] Kazemian, A., Yuan, X., Cochran, E. and Khoshnevis, B. (2017). Cementitious materials for construction-scale 3D printing: Laboratory testing of fresh printing mixture. Construction and Building Materials, 145, pp. 639-647. DOI: 10.1016/j.conbuildmat.2017.04.015. DOI: 10.1016/j.conbuildmat.2017.04.015.

[11] Perrot, A., Rangeard, D., Pierre, A. (2016). Structural built-up of cement-based materials used for 3D-printing extrusion techniques. Materials and Structures, 49, pp. 1213-1220. DOI: 10.1617/s11527-015-0571-0.

[12] Le, T., Austin, S., Lim, S., Buswell, R., Gibb, A. and Thorpe, T. (2012). Mix design and fresh properties for high-performance printing concrete. Materials and Structures, 45(8), pp. 1221-1232. DOI:10.1617/s11527-012-9828-z.

[13] Ma, L., Zhao, Y. and Gong, J. (2018). Restrained early-age shrinkage cracking properties of high-performance concrete containing fly ash and ground granulated blast-furnace slag. Construction and Building Materials, 191, pp. 1-12. DOI: 10.1016/j.conbuildmat.2018.09.154.

[14] Marchon, D., Kawashima, S., Bessaies-Bey, H., Mantellato, S. and Ng, S. (2018). Hydration and rheology control of concrete for digital fabrication: Potential admixtures and cement chemistry. Cement and Concrete Research, 112, pp. 96-110. DOI: 10.1016/j.cemconres.2018.05.014.

[15] Anastasiou, E., Liapis, A., Papachristoforou, M. (2017). Life cycle assessment of concrete products for special applications containing EAF slag, Procedia Environmental Sciences, 38, pp. 469-476. DOI: 10.1016/j.proenv.2017.03.138

[16] Anastasiou, E., Papayianni, I. (2012). Use of calcareous fly ash in SCC, Conference: EUROCOALASH 2012 Conference, Thessaloniki, Greece.

[17] Anastasiou, E., Papayianni, I., Papachristoforou, M. (2014). Behaviour of self compacting concrete containing ladle furnace slag and steel fiber reinforcement, Materials and Design, 59, pp. 454-460. DOI: 10.1016/j.matdes.2014.03.030.

[18] Sideris, K., Tassos, Ch., Chatzopoulos, A., Manita, P. (2018). Mechanical characteristics and durability of self compacting concretes produced with ladle furnace slag. Construction and Building Materials, 170, pp. 660-667. DOI: 10. 1016/j.conbuildmat.2018.03.091.

[19] Shadkam, H.R., Dadsetan, S., Tadayon, M., Sanchez, L.F.M., Zakeri, J.A. (2017). An investigation of the effects of limestone powder and viscosity modifying agent in durability related parameters of self-consolidating concrete (SCC), Construction and Building Materials, 156, pp. 152-160. DOI: 10.1016/j.conbuildmat.2017.08.165.

[20] Ling, S.K., Kwan, A.K.H. (2016). Adding limestone fines as cementitious paste replacement to lower carbon footprint of SCC, Construction and Building Materials, 111, pp. 326-336. DOI: 10.1016/j.conbuildmat.2016.02.072.

[21] Li, W., Ghazanfari, A., Leu, M.C., Landers, R.G. (2015). Methods of extrusion on demand for high solids loading ceramic paste in freeform extrusion fabrication. Proc. Solid Freeform Fabrication Symposium 2015, Austin, TX, pp. $332-345$.

[22] Koehler, E., Fowler, D. (2004). [online] Available at: https://repositories.lib.utexas.edu/handle/2152/35338.

[23] EN1015-3. (1999). Methods of test for mortar for masonry, Part 3: Determination of consistence of fresh mortar (by flow table). 
[24] ASTM C1749-17a. (2017). Standard guide for measurement of the rheological properties of hydraulic cementious paste using a rotational rheometer. DOI: 10.1520/C1749-17A

[25] Gosselin, C., Duballet, R., Roux, Ph., Gaudillière, N., Dirrenberger, J., Morel, Ph. (2016). Large-scale 3D printing of ultra-high performance concrete - A new processing route for architects and builders. Materials and Design, 100, pp. 102-109. DOI: 10.1016/j.matdes.2016.03.097.

[26] Malaeb, Z., Hachem, H., Tourbah, A., Maalouf, T., El Zarwi, N., Hamzeh, F. (2015). 3D Concrete Printing: Machine and Mix Design. International Journal of Civil Engineering and Technology, 6, pp. 14-22.

[27] ASTM C1581-04 (2004). Standard test method for determining age at cracking and induced tensile stress characteristics of mortar and concrete under restrained shrinkage. 